Canadian

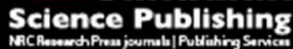

Canadian Geotechnical Journal Revue canadienne de géotechnique

\title{
Dynamic modulus characteristics of saturated clays under variable confining pressure
}

\begin{tabular}{|r|l|}
\hline Journal: & Canadian Geotechnical Journal \\
\hline Manuscript ID & cgj-2016-0441.R1 \\
\hline Manuscript Type: & Note \\
\hline Complete List of Authors: & $\begin{array}{l}\text { Gu, Chuan; Wenzhou University, College of Civil Engineering and } \\
\text { Architecture } \\
\text { Gu, Zhiqiang; Wenzhou University, College of Civil Engineering and } \\
\text { Architecture } \\
\text { Cai, Yuanqiang; Zhejiang University, } \\
\text { Wang, Jun; Wenzhou University, College of Architecture and Civil } \\
\text { Engineering } \\
\text { Ling, Dao-Sheng; Zhejiang University, College of Civil Engineering and } \\
\text { Architecture }\end{array}$ \\
\hline Keyword: & $\begin{array}{l}\text { Shear modulus, Dynamic properties, Cyclic confining pressure, Triaxial } \\
\text { tests, Clays }\end{array}$ \\
\hline & \\
\hline
\end{tabular}




\title{
Dynamic modulus characteristics of saturated clays under variable confining
}

pressure

\author{
Chuan $\mathrm{Gu}^{1}$, Zhiqiang $\mathrm{Gu}^{2}$, Yuanqiang $\mathrm{Cai}^{3}$, Jun $\mathrm{Wang}^{4}$, Daosheng Ling ${ }^{5}$
}

\footnotetext{
Associate Professor, College of Civil Engineering and Architecture, Wenzhou University, Wenzhou 325035, P.R. China. E-mail: single_k@163.com

${ }^{2}$ Master student, College of Civil Engineering and Architecture, Wenzhou University, Wenzhou 325035, P.R. China. E-mail: 1412656481@qq.com

${ }^{3}$ Professor, Research Center of Coastal and Urban Geotechnical Engineering, Zhejiang University, Hangzhou 310058, P.R. China. E-mail: caiyq@zju.edu.cn

${ }^{4}$ Professor, College of Civil Engineering and Architecture, Wenzhou University, Wenzhou 325035, P.R. China. E-mail: cleg19862008@163.com (corresponding author), Tel: +86-15067892048, Fax: +865718820887

${ }^{5}$ Professor, College of Civil Engineering and Architecture, Zhejiang University, Hangzhou 310058, P.R. China. E-mail: dsling@zju.eud.cn
} 
Abstract: Dynamic loadings, induced by earthquakes and other causes, will lead to the cyclic variation of both shear stress and normal stress components on the soil elements. A series of cyclic triaxial tests with and without variable confining pressure were carried out to investigate the coupling effects of cyclic shear stress and cyclic normal stress on the $G / G_{\max }$ characteristics of saturated clays. Results indicated that both the phase differences and ratios between the cyclic deviatoric stress and cyclic confining pressure exerted a constant and pronounced influence on the $G / G_{\max }$, indicating that the $G / G_{\max }$ properties under combined loadings will be more representative of actual field conditions than from single-loading conditions. A modified hyperbolic model considering the effects of cyclic confining pressure was further proposed.

Key words: Shear modulus; Dynamic properties; Cyclic confining pressure; Triaxial tests; Clays 


\section{Introduction}

Water-saturated, fine-grained soil deposits can be subjected to undrained cyclic loads induced by earthquakes, pile driving, explosions, ocean wave storms and other causes. The dynamic response under such loads depends to a large extent on the cyclic stress-strain characteristics of the soil in shear. Relationships between the secant shear modulus $G$ and the cyclic shear strain amplitude $\gamma$, typically expressed as a curve of $G / G_{\max }$ versus $\gamma$, are usually employed to show the modulus characteristics of soils at moderate to high strains under cyclic loadings.

Substantial research has been undertaken to elucidate the influence of soil type, void ratio, the initial state of effective stresses, overconsolidation ratio, geologic age, degree of saturation, and grain characteristics on the $G / G_{\max }$ characteristics of saturated soils (e.g., Hardin and Drnevich 1972b; Iwasaki et al. 1978; Kokusho et al. 1982; Seed et al. 1986; Vucetic 1988; Vucetic and Dobry 1991; Ishibashi and Zhang 1993; Rollins et al. 1998; Stokoe et al. 1999; Stokoe et al. 2004; Zhang et al. 2005). For example, in their summary of the effects of different factors on $G / G_{\max }$ with a specific focus on the plasticity index (PI), Vucetic and Dobry (1991) concluded that the PI correlates well with all important parameters and aspects of the cyclic behavior. Similarly, Stokoe et al. (2004) and Zhang et al. (2005) argued that that the effect of PI on dynamic soil behavior was not as significant as previously thought and suggested the confining stress and geologic age should be considered when selecting $G / G_{\max }$ curves for design. However, none of these previous studies considered the coupling of different dynamic stress components. 
Of the studies undertaken to study these couplings, Aggour and Zhang (2006) indicated that dynamic loadings induced by earthquakes were composed of very complex combinations of various waves such as compressive waves and shear waves, among others. They then used a resonant column device to simulate the combinations of different seismic waves by the combined action of cyclic axial and shear strains. Results indicated a greater reduction of the modulus under combined loadings as opposed to a single excitation. As suggested by Gu et al. (2012) and Qian et al (2106), the combined propagation of compressive waves and shear waves would lead to the cyclic variation of both shear stress components and normal stress components on the soil elements. This combined action of cyclic shear stress and cyclic normal stress components can be simulated through the coupling of cyclic deviatoric stress and cyclic confining pressure in cyclic triaxial tests with variable confining pressure (VCP tests). In comparison with the resonant column device employed by Aggour and Zhang (2006), both stress controlled and displacement controlled cyclic loadings are used in the VCP tests. It is also possible to vary the ratios and phase differences between the cyclic deviatoric stress and cyclic confining pressure, to consider more complicated conditions of the combinations of compressive and shear waves. It should be noted that although multi-directional simple shear tests have also been employed by some researchers (e.g., Kammerer et al. 2002, 2004; Rutherford 2012) to simulate the multi-directional shaking due to earthquakes and other sources, there are many differences between the VCP tests and multi-directional simple shear tests. For example, the multi-directional simple shear tests are mainly used to simulate the coupling of different shear waves rather than the coupling of compressive waves and shear waves. 
While very few studies have been undertaken to elucidate the $G / G_{\max }$ behavior of saturated soils under the coupling of cyclic deviatoric stress and cyclic confining pressure, the influences of different static stress paths in $p-q$ plane (i.e., the coupling of deviatoric stress and mean principal stress) on the stress-strain responses of saturated soils have been studied (e.g., Gasparre et al. 2007, Cho and Finno 2010; Finno and Cho 2011). For example, based upon their substantial testing of drained static stress paths on Chicago glacial clays over a wide strain range, Cho and Finno (2010) observed that the secant shear and bulk moduli obtained at strain levels greater than $0.002 \%$ depended strongly upon the loading direction and strain level. Further, they also observed a decrease in the dependence of these moduli on the stress path direction with an increasing strain for both the shearing and volumetric behaviors. It is speculated that the $G / G_{\max }$ behavior of saturated soils under cyclic loadings may also be related to the dynamic stress paths in the $p-q$ plane.

In this study, a series of stress-controlled and staged cyclic triaxial tests with and without variable confining pressure were conducted on two different remolded saturated clays, in which two phase differences and several ratios between the cyclic deviatoric stress and cyclic confining pressure were employed. Test results show that both the phase differences and ratios influence the $G / G_{\max }$ characteristics greatly and regularly, implying that the $G / G_{\max }$ relationships under combined loadings cannot be determined simply by conventional tests that only apply a single cyclic loading. A modified hyperbolic model considering the effects of cyclic confining pressure is therefore proposed. 


\section{Test Apparatus, Test Materials and Experimental Program}

The tests in this study were conducted using a combination device of a piezoelectric-ceramic bender element system and an advanced cyclic triaxial apparatus (Gu et al. 2014), which was designed and manufactured by the GDS Corporation in Great Britain. The bender elements are set into the top and bottom platens of the triaxial cell. The advanced cyclic triaxial apparatus can control both the amplitudes of the cyclic deviator stress and cyclic confining pressure, and independent phase difference between the two. The vertical stress is applied by a servo-loading system, while the confining pressure is supplied through an oil pressure type piston. The measurement of axial displacement had an accuracy of approximately $0.5 \mu \mathrm{m}$, resulting a strain accuracy of approximately $0.005 \%$ at a height of $100 \mathrm{~mm}$.

To facilitate the investigation into the coupling effects of cyclic deviator stress and cyclic confining pressure, the parameter $\eta^{a m p l}$ was introduced, using a procedure developed by Gu et al. (2012) and Sun et al. (2015). As shown in Fig. 1, $q^{a m p l}$ is the amplitude of cyclic deviator stress, and $\sigma_{3}^{a m p l}$ is the amplitude of cyclic confining pressure. $p^{a m p l}$ is the amplitude of cyclic mean principal stress, which is calculated by $p^{a m p l}=\left(\sigma_{1}^{a m p l}+2 \sigma_{3}^{a m p l}\right) / 3=\sigma_{3}^{a m p l}+q^{a m p l} / 3 . \eta^{a m p l}$ is defined as $p^{a m p l} / q^{a m p l}$. In cyclic triaxial tests with constant confining pressure (CCP tests), $\eta^{a m p l}=1 / 3$. In VCP tests, the two representative values of the phase angle $\theta$, i.e., $\theta=0^{\circ}$ and $\theta=180^{\circ}$ were employed to study the influence of phase differences on the $G / G_{\max }$ characteristics. When $\theta=0^{\circ}, \eta^{a m p l}=1 / 3+\sigma_{3}^{a m p l} / q^{a m p l}$, and when $\theta=180^{\circ}, \eta^{a m p l}=1 / 3-\sigma_{3}^{a m p l} / q^{a m p l}$. In Fig. 1 , the inclinations of the stress paths in $p$ - $q$-plane signify the $\eta^{\text {ampl }}$ values. 
In order to remove the influences of initial soil fabric and overconsolidation on $G / G_{\max }$ characteristics, remolded clays were selected as the test materials. The original clays used for the preparation of remolded samples were obtained from 6-9 meters beneath the ground surface, from two sites in Wenzhou city, which is in eastern coastal China and well-known for its soft clay deposits. The soft clays in Wenzhou city are mostly marine deposits and can reach a depth of $150 \mathrm{~m}$. One site is in the campus of Wenzhou University and the other is close to the Oujiang River. In this study, the two clays are named WZU clay and WZO clay, respectively, the primary physical index properties of which are summarized in Table 1. According to the USCS classification method, both the WZU and WZO clays are classified as $\mathrm{CH}$.

A standard routine sample preparation procedure was employed to guarantee the consistency of the sample quality (Gu et al. 2012 and Cai et al. 2013). First, the original clay was dried in an oven and then ground to a powder followed by the preparation of a sample of clay slurry with water content equal to the liquid limit $w_{\mathrm{L}}$. After being mixed and de-aired thoroughly, the slurry was pre-consolidated in a large consolidation vessel under a vertical pressure of $50 \mathrm{kPa}$ for a month. Finally, cylindrical specimens with a diameter of $50 \mathrm{~mm}$ and a height of $100 \mathrm{~mm}$ were trimmed from the consolidated blocks and then mounted in the triaxial cell. Subsequently, a back pressure of $300 \mathrm{kPa}$ with an effective stress of $10 \mathrm{kPa}$ was applied, until $B$ values greater than 0.97 were achieved. The specimens were then isotropically consolidated under selected effective confining pressures.

After consolidation, the bender element test was first conducted to obtain the small-strain shear modulus $G_{\max }$. A combined action of cyclic deviator stress and cyclic confining pressure 
was then applied in stages. For each loading stage, 11 cycles were applied on the specimen under undrained conditions, followed by a period of pore-pressure equalization. The next 11 cycles with larger amplitudes of both cyclic deviatoric stress and cyclic confining pressure were then subsequently applied with the same parameter of $\eta^{a m p l}$. This process was repeated until the cyclic axial strain amplitude reached approximately $2 \%$. The numbers of loading stages for all tests are set at 11. It should be noted that the amplitudes of cyclic loadings (including both cyclic deviatoric stress and cyclic confining pressure) at the same loading stage but among different specimens are varied to optimize according to the results of preliminary tests. Following a procedure developed by Tatsuoka et al. (2001) and Yamada et al. (2008), the dynamic properties were calculated from the 10th cycle data of each loading stage.

The detailed test program is summarized in Table 2, including 7 tests on WZU clay and 12 tests on WZO clay. Two values of effective confining pressure $\left(p_{0}^{\prime}=100 \mathrm{kPa}\right.$ and $\left.200 \mathrm{kPa}\right)$ and seven values of $\eta^{a m p l}\left(\eta^{a m p l}=1 / 3,1.0,1.5,2,-1.0,-1.5\right.$, and -2.0) were employed. Tests were conducted at a low frequency of $0.1 \mathrm{~Hz}$ for WZU clay and $0.01 \mathrm{~Hz}$ for WZO clay, respectively. These slow loading frequencies were selected because of their lack of effect on the initial shear modulus (Shibuya et al. 1995) and can make the application of cyclic confining pressure more accurate. 


\section{$G / G_{\max }$ versus $\gamma$ relationships under variable confining pressure}

The time-history curves of cyclic deviatoric and cyclic confining pressure from three typical tests are presented in Fig. 2a (WZO clay, $p_{0}^{\prime}=100 \mathrm{kPa}, \eta^{a m p l}=1.5$ ), Fig. 3a (WZO clay, $\left.p_{0}^{\prime}=100 \mathrm{kPa}, \eta^{a m p l}=1 / 3\right)$ and Fig.4a (WZO clay, $\left.p_{0}^{\prime}=100 \mathrm{kPa}, \eta^{a m p l}=-1.5\right)$, respectively, while the hysteresis loops from the same three tests are shown in Fig. 2(b) and Fig. 3(b) and Fig. 4(b), respectively. Both the time-history curves and hysteresis loops include all loading cycles in every loading stage.

The cyclic deviatoric stress and cyclic confining pressure were applied at the same phase $\left(\theta=0^{\circ}\right)$, the results of which are shown in Fig. 2(a). The condition of the opposite phase $\left(\theta=180^{\circ}\right)$ is shown in Fig. 4(a) and the constant confining pressure is shown in Fig. 3(a). Although there were no significant visible differences between the three hysteresis loops, the calculations based on the whole test data indicated that the ratio of the maximum compression strain to the maximum tension strain at the same loading cycle decreased gradually with an increase in $\eta^{a m p l}$ values. This decrease indicates that the tension strain is produced faster than the compression strain does with an increase in $\eta^{a m p l}$ values. The mechanism resulting from this phenomenon has been carefully elucidated by Gu et al. (2012), which indicated that in the effective stress paths of tests under $\eta^{a m p l}>0$, the effective stresses in the tensile half cycle (i.e., $q<0$ ) are lower than those in the compressive half cycle (i.e., $q>0$ ), and this trend is reversed gradually when the $\eta^{a m p l}$ value is decreasing.

In cyclic triaxial tests, the dynamic elastic modulus is determined by $E=q / \varepsilon_{a}$, in which $\varepsilon_{a}$ is the amplitude of cyclic axial strain in a hysteresis loop and $q$ is the amplitude of cyclic 
deviatoric stress corresponding to $\varepsilon_{a}$. Considering that most studies on the dynamic secant modulus behavior used the parameters of shear modulus $G$ and shear strain $\gamma, E$ and $\varepsilon_{a}$ were transformed to $G$ and $\gamma$ for our purposes here. Further, as the Poisson ratio $v$ is 0.5 for saturated soils, the modulus is expressed as:

$$
\begin{gathered}
G=\frac{E}{2(1+v)}=\frac{E}{3} \\
\gamma=(1+v) \varepsilon=1.5 \varepsilon_{a}
\end{gathered}
$$

The preliminary tests indicated that the average densities $\rho$ of samples after the consolidation under $p_{0}^{\prime}=100 \mathrm{kPa}$ and $200 \mathrm{kPa}$ were $1.72 \mathrm{~g} / \mathrm{cm}^{3}$ and $1.79 \mathrm{~g} / \mathrm{cm}^{3}$ for WZU clay and $1.74 \mathrm{~g} / \mathrm{cm}^{3}$ and $1.80 \mathrm{~g} / \mathrm{cm}^{3}$ for WZO clay, respectively. The results of the bender element tests showed that the average shear wave velocities $V_{\mathrm{s}}$ under $p_{0}^{\prime}=100 \mathrm{kPa}$ and $200 \mathrm{kPa}$ were $97.2 \mathrm{~m} / \mathrm{s}$ and $122.5 \mathrm{~m} / \mathrm{s}$ for WZU clay and $102.1 \mathrm{~m} / \mathrm{s}$ and $134.2 \mathrm{~m} / \mathrm{s}$ for WZO clay, respectively. As the small-strain shear modulus $G_{\max }$ can be calculated based on $G_{\max }=\rho V_{s}^{2}$, the average $G_{\max }$ under $p_{0}^{\prime}=100 \mathrm{kPa}$ and $200 \mathrm{kPa}$ was $16.3 \mathrm{MPa}$ and $26.8 \mathrm{MPa}$ for the WZU clay and 18.1 $\mathrm{MPa}$ and 32.4 MPa for the WZO clay, respectively.

The $G / G_{\max }$ versus $\gamma$ relationships for the WZU and WZO clays are shown in Figs. 5 and 6 , respectively. Note the effects of cyclic confining pressure on the $G / G_{\max }$ properties in which the increase of $\eta^{a m p l}$ values causes a decrease in the $G / G_{\max }$ curves. Compared to the results of CCP tests at the same shear strain, the coupling of cyclic deviatoric stress and cyclic confining pressure at the same phase (i.e., $\theta=0^{\circ}$ ) will reduce the $G / G_{\max }$ values. This decrease will in turn expand with an increase in the ratios of the cyclic confining pressure amplitude to the cyclic 
deviatoric stress amplitude. Conversely, for the VCP tests at the opposite phase (i.e., $\theta=180^{\circ}$ ), the $G / G_{\max }$ values increase gradually with an increase in the corresponding ratios. Take Fig. 6(a) as an example (WZO clay, $p_{0}^{\prime}=100 \mathrm{kPa}$ ), the stress path under $\eta^{a m p l}=2.0$ and $\eta^{a m p l}=-2.0$ delivers an approximate $-14 \%$ and $+16 \%$ increment of the $G / G_{\max }$ value, respectively, compared with that obtained in the CCP test $\left(\eta^{\mathrm{ampl}}=1 / 3\right)$. These results indicate that the $G / G_{\max }$ relationships under combined loadings, which are more representative of actual field conditions, cannot be determined simply by conventional tests that only apply a single loading.

Within the strain range of approximate $0.007 \%$ to $2 \%$ measured in this study, the differences of $G / G_{\max }$ values between every two stress paths changed greatly with a variation of shear strains. At large shear strains, as the shear strain increases the change in the shear modulus reduction curve for different $\eta^{\text {ampl }}$ values decreases, eventually becoming negligible.

Gu et al. (2012) indicated that although the coupling of cyclic deviatoric stress and cyclic confining pressure has little effect on the residual excess pore water pressure of saturated clays, it has complicated influences on the development of axial strain and the shapes of effective stress paths. The ratio of the maximum compression strain to maximum tension strain during a single loading cycle is also related to the cyclic confining pressure. It is speculated that all these changes of dynamic properties under the coupling of cyclic deviatoric stress and cyclic confining pressure may lead to the behavior of dynamic modulus. 


\section{Hyperbolic model considering the effects of variable confining pressure}

Hyperbolic models, such as that developed by Harden and Drnevich (1972a), have been used to describe the nonlinear soil behavior under cyclic loadings. In this particular model, a hyperbola asymptotic to the maximum shear stress is used to represent the stress-strain curve of the soil. Unfortunately, the single curve-fitting variable of this simple hyperbolic model makes it a poor fit for the test data. In this study, the authors used a hyperbolic model modified from procedures developed by Stokoe et al. (1999) and Zhang et al. (2005) to fit the $G / G_{\max }$ versus $\gamma$ relationships under cyclic confining pressure, which is expressed as:

$$
\frac{G}{G_{\max }}=\frac{1}{1+\left(\frac{\gamma}{\gamma_{\mathrm{r}}}\right)^{\alpha}}
$$

Unlike the reference strain used in the single curve fitting model developed by Hardin and Drnevich (1972a), two curve-fitting variables are used here; $\gamma_{\mathrm{r}}$ is the reference strain that corresponds to the shear strain when $G / G_{\max }=0.5$, with $\alpha$ serving as the fitting parameter.

The test data of both clays under $p_{0}^{\prime}=100 \mathrm{kPa}$ was used to fit Eq. (3), while the test results under $p_{0}^{\prime}=200 \mathrm{kPa}$ was used for the verification of the fitting equation. Multiple regression was then used to determine the $\alpha$ values that provide the closest fit to the compiled test data. Table 3 presents all of the $\gamma_{\mathrm{r}}$ and $\alpha$ values, and shows that there is a general increase in the values of both $\gamma_{\mathrm{r}}$ and $\alpha$ with a corresponding decrease in the $\eta^{\text {ampl }}$ values.

The comparison between the fitting curves based on Eq. (3) and the measured test data are shown in Fig. 7, in which Fig. 7(a) and Fig. 7(b) are the results of WZU clay and WZO clay, respectively. The values of $\gamma_{\mathrm{r}}$ and $\alpha$ for every test and the values of adjusted $\mathrm{R}^{2}$ for every fitting 
curve are also plotted in the figures. It can be seen that almost all $\mathrm{R}^{2}$ values are above 0.99 , implying that Eq. (3) can well reflect the influences of cyclic confining pressure on the $G / G_{\max }$ characteristics, through varying $\alpha$ values. The increase of the $\eta^{a m p l}$ values causes a gradual decrease of the fitting curves.

The relationships between $\alpha$ and $\eta^{\text {ampl }}$ for both clays are show in Fig. 8, indicating a linear relationship between all of them regardless of different soil types and loading frequencies. This close correlation also clearly indicates a simple formula can be used to quantitatively express the effects of cyclic confining pressure on the $G / G_{\max }$ curves. These findings will be of use in elucidating and determining the $G / G_{\max }$ characteristics of saturated soils under combined loadings. However, the limitations of the test data means that extensive research is still needed to determine the factors affecting the $G / G_{\max }$ curves under variable confining pressures.

The fitted linear equation is expressed as:

$$
\alpha=0.65644-0.07736 \times \eta^{a m p l}
$$

The $\gamma_{\mathrm{r}}$ and $\alpha$ values of the 7 tests under $p_{0}^{\prime}=200 \mathrm{kPa}$ are presented in Table 4, in which all the $\alpha$ values are calculated by Eq. (4). A comparison between the test data and the prediction by Eq. (3), presented in Fig. 9, shows that the predicted results closely agree with the measured test data, particularly within the shear strain range of $0.01 \%$ to $0.5 \%$. These results indicate a good prediction quality for the $G / G_{\max }$ characteristics under the complex stress paths of cyclic deviatoric stress and cyclic confining pressure. 


\section{Conclusions}

In this study, a series of stress-controlled and staged cyclic triaxial tests both with and without variable confining pressure were conducted on two remolded saturated clays, to investigate the coupling effects of cyclic deviator stress and cyclic confining pressure on the $G / G_{\max }$ characteristics. The major conclusions from these tests are summarized as follows:

(1) Both the phase differences and ratios in the coupling of cyclic deviatoric stress and cyclic confining pressure had a pronounced and significant influence on the $G / G_{\max }$ characteristics, implying that conventional tests alone, which use only a single loading, are inadequate for determining the $G / G_{\max }$ relationships under combined loadings.

(2) A proposed modified hyperbolic model considering the effects of cyclic confining

pressure was used, in which the fitting parameter $\alpha$ was linear to the $\eta^{\text {ampl }}$. The modified hyperbolic model was also closely verified through the use of other test data.

\section{Acknowledgements}

The work was supported the National Key Research and Development Program of China (No. 2016YFC0800203), the National Natural Science Foundation of China (No. 51578426), the National Basic Research Program (973 Program) of China (No. 2014CB047005), and the Provincial Nature Science Foundation of Zhejiang (No. LY17E080011). 


\section{References}

Aggour, M. S., and Zhang, J. X. 2006. "Degradation of Sands due to Combined Sinusoidal Loading. " J. Geotech. Geoenviron. Eng., 132(12), 1628-1632.

Cai, Y. Q., Gu, C., Wang, J., Juang, C. H., Xu, C. J., and Hu, X. Q. 2013. "One-Way Cyclic Triaxial Behavior of Saturated Clay: Comparison between Constant and Variable Confining Pressure.” J. Geotech. Geoenviron. Eng., 139(5), 797-809.

Cho, W., and Finno, R. J. 2010. "Stress-Strain Responses of Block Samples of Compressible Chicago Glacial Clays.” J. Geotech. Geoenviron. Eng., 136(1), 178-188.

Finno, R. J., and Cho, W. 2011. "Recent Stress-History Effects on Compressible Chicago Glacial Clays.” J. Geotech. Geoenviron. Eng., 137(3), 197-207.

Gasparre, A., Nishimura, S., Minh, N. A., Coop, M. R., and Jardine, R. J. 2007. "The stiffness of natural London clay.” Geotechnique, 571, 33-47.

Gu, C., Wang J., Cai, Y. Q., and Guo, L. 2014. "Influence of cyclic loading history on small strain shear modulus of saturated clays. " Soil Dynamics and Earthquake Engineering, 66, 1-12.

Gu, C., Wang, J., Cai, Y. Q., Yang, Z. X., and Gao, Y. F. 2012. "Undrained cyclic triaxial behavior of saturated clays under variable confining pressure." Soil Dynamics and Earthquake Engineering, 40, 118-128.

Hardin, B. O., and Drnevich, V. P. 1972a. "Shear modulus and damping in soils." J. Soil Mech. Found. Div., 98(7), 667-692. 
Hardin, B. O., and Drnevich, V. P. 1972b. "Shear modulus and damping in soils: Measurement and parameter effects (Terzaghi Lecture)." J. Soil Mech. Found. Div., 98(6), 603-624.

Ishibashi, I., and Zhang, X. J. 1993. "Unified dynamic shear moduli and damping ratios of sand and clay." Soils Found., 33(1), 182-191.

Iwasaki, T., Tatsuoka, F., and Takagi, Y. 1978. "Shear moduli of sands under cyclic torsional shear loading." Soils Found., 18(1), 39-56.

Kammerer, A. M., Pestana J. M., and Seed, R. B.2002. "Undrained Response of Monterey 0/30 Sand Under Multidirectional Cyclic Simple Shear Loading Conditions." Geotechnical Engineering Research Report No. UCB/GT/02-01, University of California, Berkeley.

Kammerer, A. M., Wu J., Riemer M., Pestana J. M., and Seed, R. B. 2004. "Shear shears strain development in liquefiable soil under bi-directional loading conditions." In proceeding of 13th World Conference on Earthquake Engineering, Paper 2081, Vancouver, B.C., Canada.

Kokusho, T., Yoshida, Y., and Esashi, Y. 1982. "Dynamic properties of soft clay for wide strain range." Soils Found., 22(4), 1-18.

Qian J. G., Wang Y. G., Yin Z. Y., and Huang, M. S. 2016. "Experimental identification of plastic shakedown behavior of saturated clay subjected to traffic loading with principal stress rotation." Engineering Geology, 214, 29-42.

Rollins, K. M., Evans, M. D., Diehl, N. B., and Daily, W. D., III 1998. "Shear modulus and damping relationships for gravels." J. Geotech. Geoenviron. Eng., 124(5), 396-405. 
Rutherford C. J. 2012. "Development of a multi-directional direction simple shear testing device for characterization of the cyclic shear response of marine clays." Ph.D. thesis, Texas A\&M University, Texas.

Seed, H. B., Wong, R. T., Idriss, I. M., and Tokimatsu, K. 1986. "Moduli and damping factors for dynamic analysis of cohesionless soils.” J. Geotech. Eng., 112(11), 1016-1032.

Shibuya, S., Mitachi, T., Fukuda, F., and Degoshi, T. 1995. "Strain rate ffect on the shear modulus and damping of normally consolidated clay.” Geotech. Test. J., 183, 365-375.

Stokoe, K. H., II, Darendeli, M. B., Andrus, R. D., and Brown, L. T. 1999. "Dynamic soil properties: Laboratory, field and correlation studies." Proc., 2nd Int. Conf. on Earthquake Geotechnical Engineering, Vol. 3, Lisbon, Portugal, 811-845.

Stokoe, K. H., II, Darendeli, M. B., Gilbert, R. B., Menq, F. Y., and Choi, W. K. 2004. "Development of a new family of normalized modulus reduction and material damping curves." Proc., NSF/PEER Int. Workshop on Uncertainties in Nonlinear Soil Properties and their Impact on Modeling Dynamic Soil Response, Univ. of California at Berkeley, Berkeley, Calif.

Sun, L., Gu, C., and Wang, P. 2015. "Effects of cyclic confining pressure on the deformation characteristics of natural soft clay." Soil Dynamics and Earthquake Engineering, 78, 99-109.

Tatsuoka, F., Shibuya, S., and Kuwano, R. 2001. "Advanced laboratorystress-strain testing of geomaterials.” Balkema, Rotterdam, The Netherlands, 92-110. 
Vucetic, M. 1988. "Normalized behavior of offshore clay under uniform cyclic loading." Can. Geotech. J., 25(1), 33-42.

Vucetic, M., and Dobry, R. 1991. "Effect of soil plasticity on cyclic response." J. Geotech. Eng., $117(1), 89-107$.

Yamada S., Hyodo M., Orense R. P., and Dinesh, S. V. 2008. "Initial Shear Modulus of Remolded Sand-Clay Mixtures.” J. Geotech. Geoenviron. Eng.,134(7), 960-971.

Zhang, J. F., Andrus, R. D., and Juang, C. H. 2005. "Normalized shear modulus and material damping ratio relationships." J. Geotech. Geoenviron. Eng., 131(4), 453-464. 


\section{Figures captions}

Fig. 1. The stress paths employed in this study

Fig. 2. (a) Time-history curves of the cyclic deviatoric stress and the cyclic confining pressure and (b) the hysteresis loops for WZO clay, $p_{0}^{\prime}=100 \mathrm{kPa}$ and $\eta^{a m p l}=1.5$

Fig. 3. (a) Time-history curves of the cyclic deviatoric stress and the cyclic confining pressure and (b) the hysteresis loops for WZO clay, $p_{0}^{\prime}=100 \mathrm{kPa}$ and $\eta^{a m p l}=1 / 3$

Fig. 4. (a) Time-history curves of the cyclic deviatoric stress and the cyclic confining pressure and (b) the hysteresis loops for WZO clay, $p_{0}^{\prime}=100 \mathrm{kPa}$ and $\eta^{a m p l}=-1.5$

Fig. 5. $G / G_{\max }$ versus $\gamma$ relationships for WZU clay: (a) $p_{0}^{\prime}=100 \mathrm{kPa}$; (b) $p_{0}^{\prime}=200 \mathrm{kPa}$

Fig. 6. $G / G_{\max }$ versus $\gamma$ relationships for WZO clay: (a) $p_{0}^{\prime}=100 \mathrm{kPa}$; (b) $p_{0}^{\prime}=200 \mathrm{kPa}$

Fig. 7. Comparison between the fitting curves based on Eq. (3) and measured test data for: (a) WZU clay; (b) WZO clay

Fig. 8. Relationships between $\alpha$ and $\eta^{a m p l}$

Fig. 9. Comparison between the test data and the predicted results for: (a) WZU clay; (b) WZO clay 
Table 1. The physical index properties of the two remolded clays used in this study

\begin{tabular}{cccccccc}
\hline Soil type & $G_{s}{ }^{\mathrm{a}}$ & $\begin{array}{c}w^{\mathrm{b}} \\
(\%)\end{array}$ & $\begin{array}{c}w_{p}{ }^{\mathrm{c}} \\
(\%)\end{array}$ & $\begin{array}{c}w_{L}{ }^{\mathrm{d}} \\
(\%)\end{array}$ & $I_{p}{ }^{\mathrm{e}}$ & $\begin{array}{c}\mathrm{Pc}^{\mathrm{f}} \\
(\%)\end{array}$ & $\begin{array}{c}\mathrm{Fc}^{\mathrm{g}} \\
(\%)\end{array}$ \\
\hline $\begin{array}{c}\text { WZU } \\
\text { clay }\end{array}$ & 2.74 & $58.0 \sim 62.0$ & 31 & 71 & 40 & 57 & 96 \\
$\begin{array}{c}\text { WZO } \\
\text { clay }\end{array}$ & 2.69 & $47.0 \sim 51.0$ & 36 & 61 & 25 & 44 & 94 \\
\hline
\end{tabular}

Note: ${ }^{\mathrm{a}} G_{S}=$ specific gravity; ${ }^{\mathrm{b}}{ }=$ water content; ${ }^{\mathrm{c}} w_{p}=$ plasticity limit; ${ }^{\mathrm{d}} w_{L}=$ liquid limit; ${ }^{\mathrm{e}} I_{p}=$ plasticity index; ${ }^{\mathrm{f}} \mathrm{Pc}=$ clay content; ${ }^{\mathrm{g}} \mathrm{Fc}=$ fines content.

Table 2. Summary list of the present tests

\begin{tabular}{ccccc}
\hline Soil type & $\begin{array}{c}p_{0}^{\prime} \\
(\mathrm{kPa})\end{array}$ & $\begin{array}{c}\text { Loading } \\
\text { frequency }\end{array}$ & $\begin{array}{c}\text { Number of } \\
\text { loading stages }\end{array}$ & $\eta^{\text {ampl }}=p^{\text {ampl } / q^{\text {ampl }}}$ \\
\hline WZU clay & 100 & $0.1 \mathrm{~Hz}$ & 11 & $1 / 3 ; 1.5 ;-1.5 ; 2.0 ;-2.0$ \\
WZU clay & 200 & $0.1 \mathrm{~Hz}$ & 11 & $-1.5 ; 2.0$ \\
WZO clay & 100 & $0.01 \mathrm{~Hz}$ & 11 & $1 / 3 ; 1.0 ;-1.0 ; 1.5 ;-1.5 ; 2.0 ;-2.0$ \\
WZO clay & 200 & $0.01 \mathrm{~Hz}$ & 11 & $1 / 3 ; 1.0 ;-1.0 ; 1.5 ;-1.5$ \\
\hline
\end{tabular}

Table 3. The values of $\gamma_{\mathrm{r}}$ and $\alpha$ under $p_{0}^{\prime}=100 \mathrm{kPa}$

\begin{tabular}{ccc|ccc}
\hline & WZU clay & & \multicolumn{3}{c}{ WZO clay } \\
\hline$\eta^{\text {ampl }}$ & $\gamma_{\mathrm{r}}(\%)$ & $\alpha$ & $\eta^{\text {ampl }}$ & $\gamma_{\mathrm{r}}(\%)$ & $\alpha$ \\
2.0 & 0.0841 & 0.5058 & 2.0 & 0.0532 & 0.4960 \\
1.5 & 0.1447 & 0.5727 & 1.5 & 0.0672 & 0.5243 \\
$1 / 3$ & 0.1522 & 0.6265 & 1.0 & 0.0939 & 0.5781 \\
-1.5 & 0.2406 & 0.7538 & $1 / 3$ & 0.1056 & 0.6140 \\
-2.0 & 0.2890 & 0.8117 & -1.0 & 0.1233 & 0.7475 \\
-- & -- & -- & -1.5 & 0.1404 & 0.7666 \\
-- & -- & -- & -2.0 & 0.1721 & 0.8287 \\
\hline
\end{tabular}


Table 4. The values of $\gamma_{\mathrm{r}}$ and $\alpha$ under $p_{0}^{\prime}=200 \mathrm{kPa}$

\begin{tabular}{ccc|ccc}
\hline & WZU clay & & \multicolumn{3}{c}{ WZO clay } \\
\hline$\eta^{\text {ampl }}$ & $\gamma_{\mathrm{r}}(\%)$ & $\alpha$ & $\eta^{\text {ampl }}$ & $\gamma_{\mathrm{r}}(\%)$ & $\alpha$ \\
2.0 & 0.0856 & 0.5017 & 1.5 & 0.0389 & 0.5404 \\
-1.5 & 0.3051 & 0.7725 & 1.0 & 0.0836 & 0.5791 \\
-- & -- & -- & $1 / 3$ & 0.1169 & 0.6307 \\
-- & -- & -- & -1.0 & 0.2229 & 0.7338 \\
-- & -- & -- & -1.5 & 0.2818 & 0.7725 \\
\hline
\end{tabular}




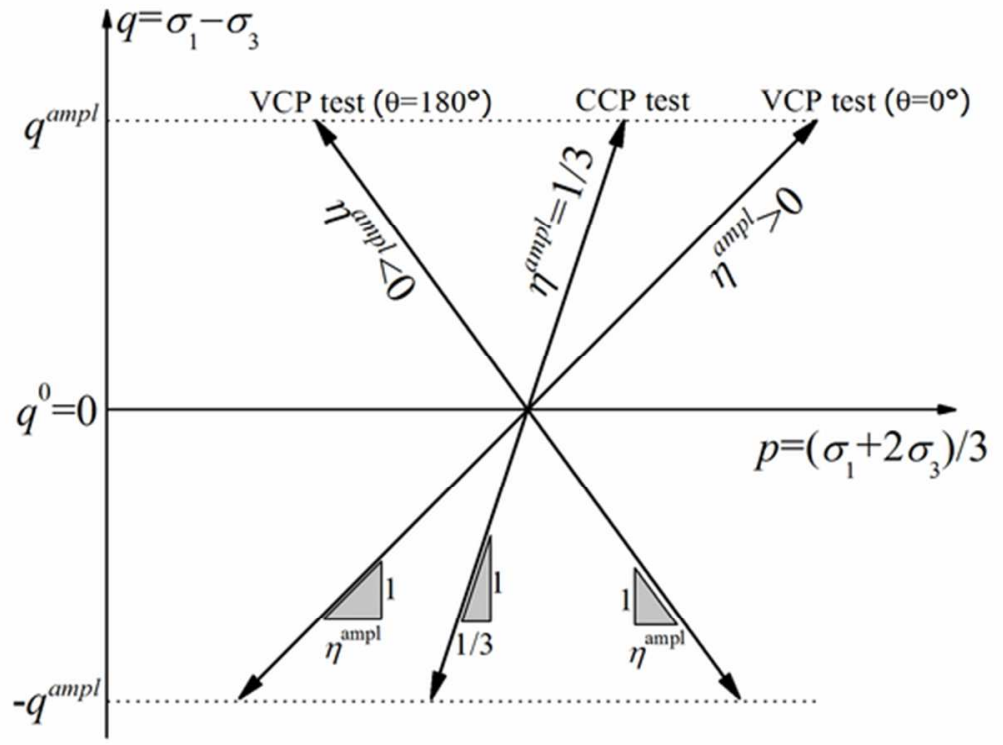

Fig. 1. The stress paths employed in this study

$60 \times 42 \mathrm{~mm}(300 \times 300$ DPI $)$ 

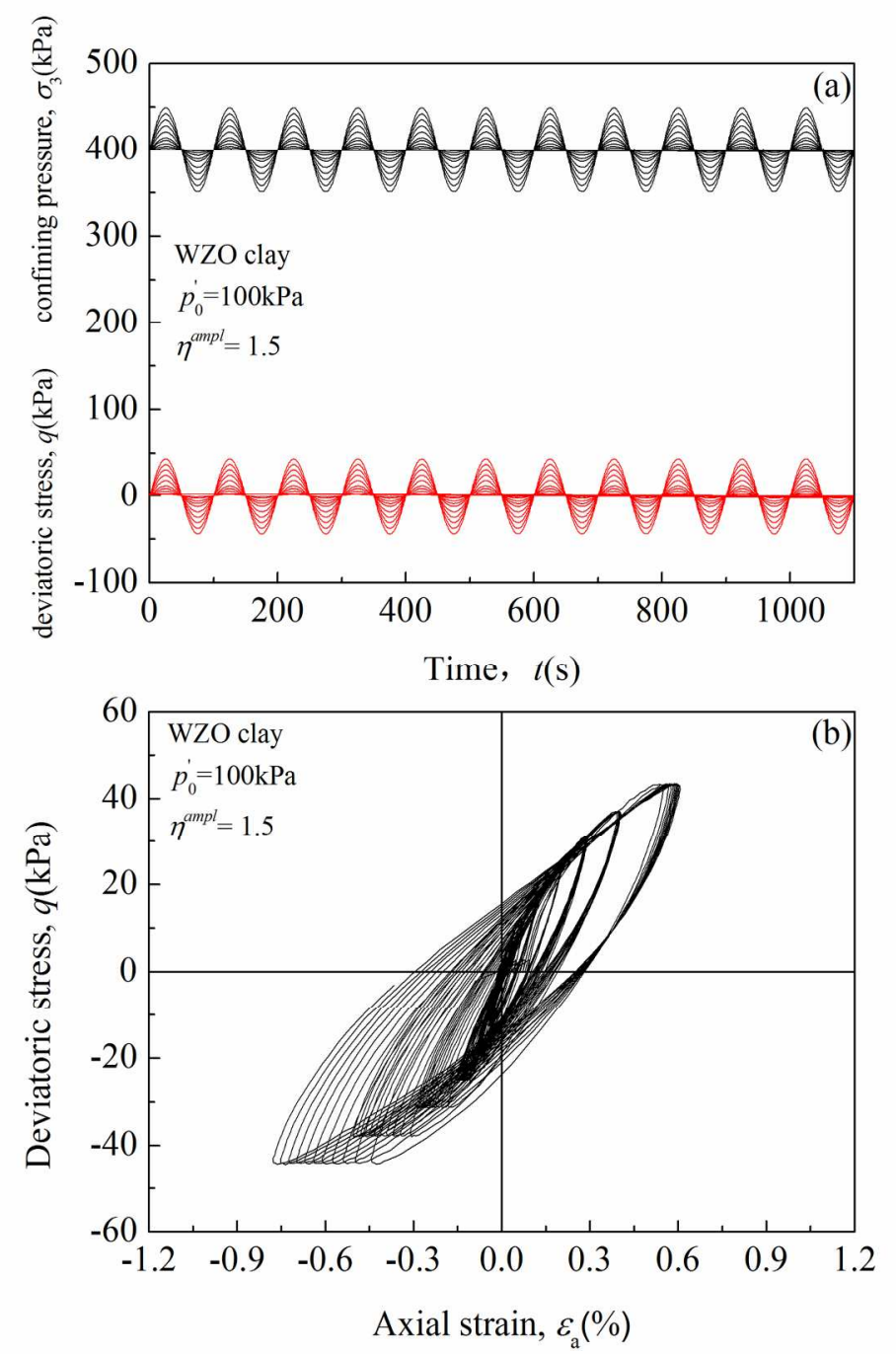

Fig. 2. (a) Time-history curves of the cyclic deviatoric stress and the cyclic confining pressure and (b) the hysteresis loops for WZO clay, $p_{0}^{\prime}=100 \mathrm{kPa}$ and $\eta^{a m p l}=1.5$

$136 \times 218 \mathrm{~mm}(300 \times 300 \mathrm{DPI})$ 

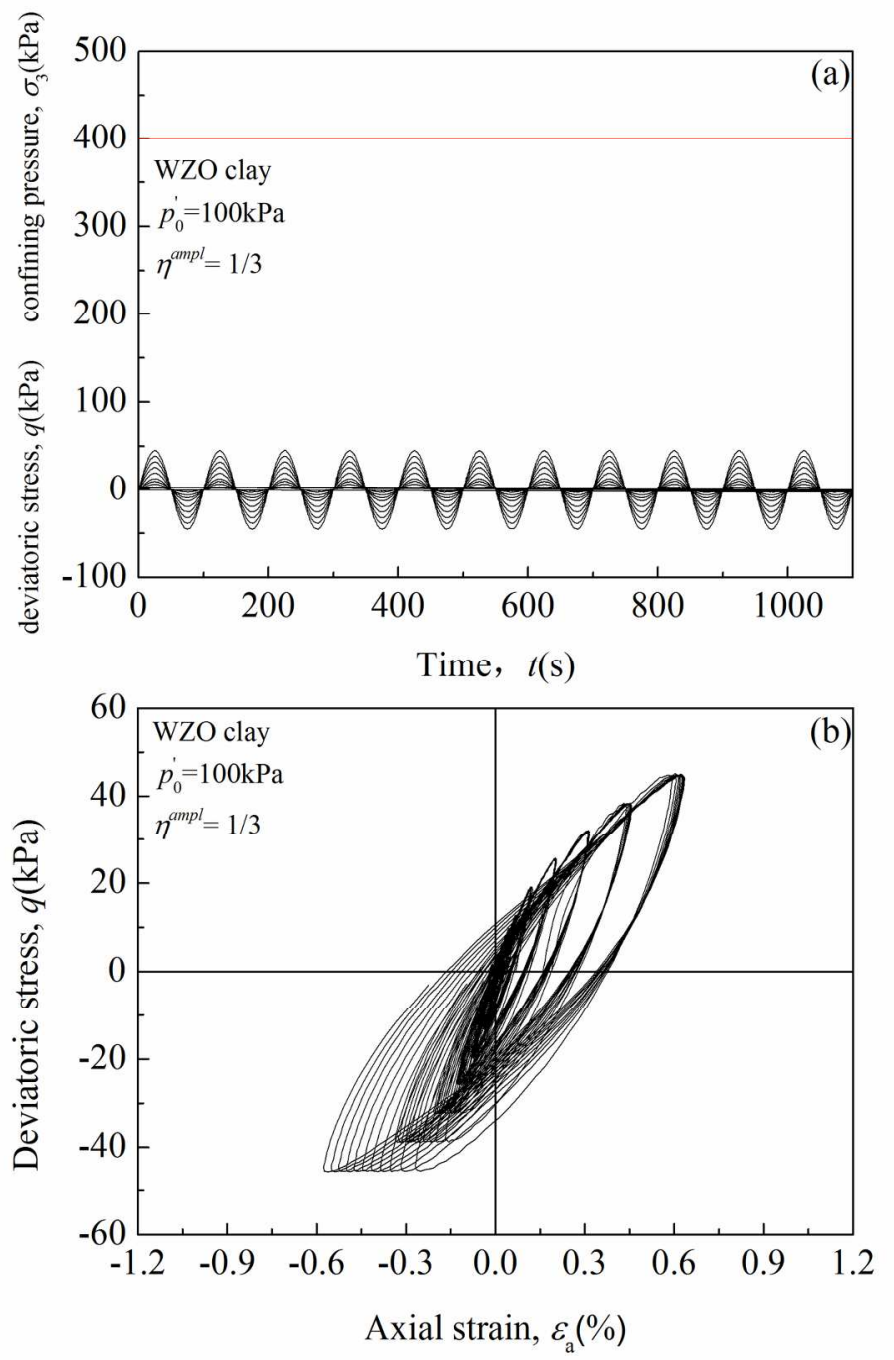

Fig. 3. (a) Time-history curves of the cyclic deviatoric stress and the cyclic confining pressure and (b) the hysteresis loops for WZO clay, $p_{0}^{\prime}=100 \mathrm{kPa}$ and $\eta^{\text {ampl }}=1 / 3$

$136 \times 218 \mathrm{~mm}(300 \times 300 \mathrm{DPI})$ 

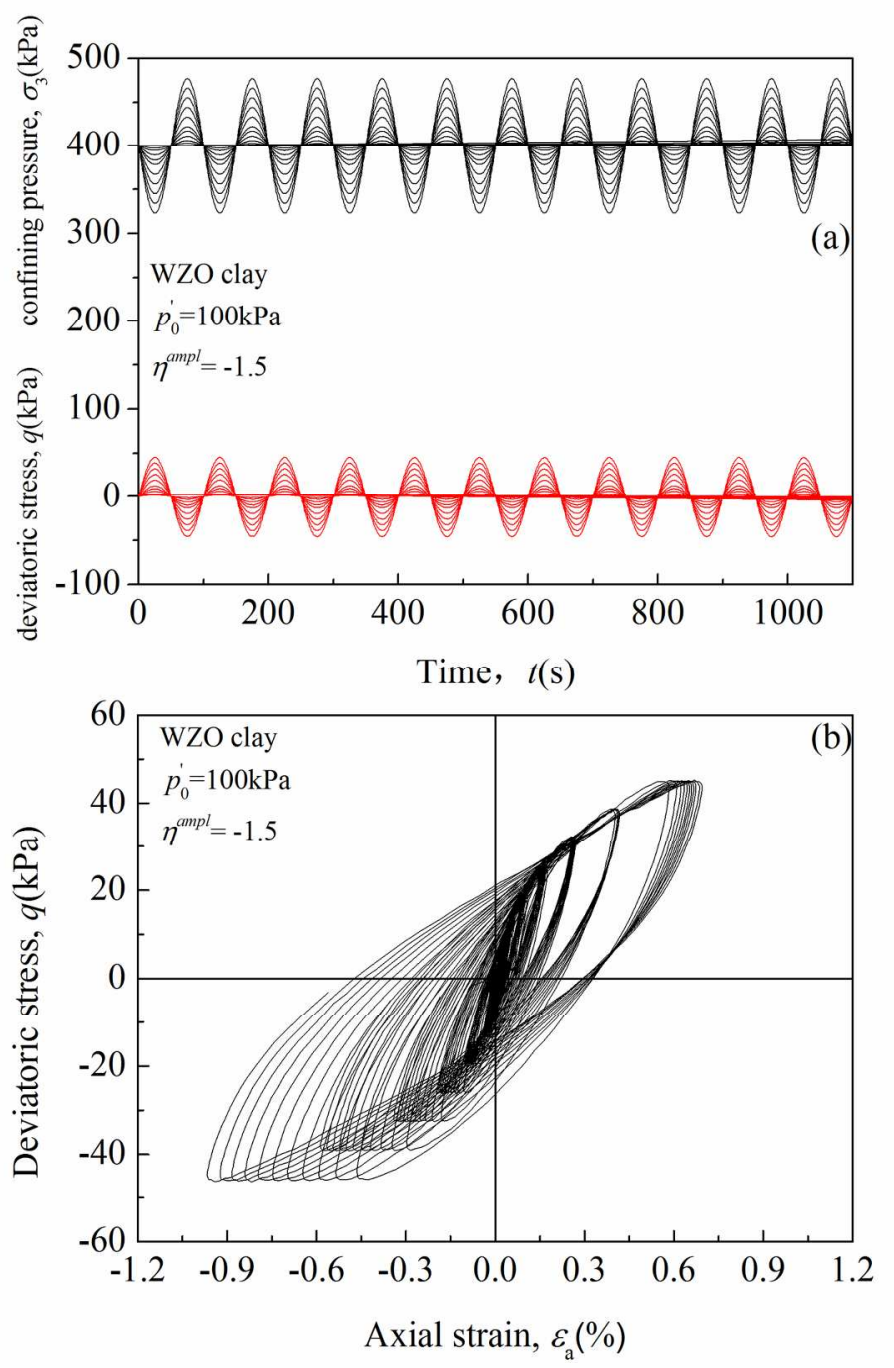

Fig. 4. (a) Time-history curves of the cyclic deviatoric stress and the cyclic confining pressure and (b) the hysteresis loops for WZO clay, $p_{0}=100 \mathrm{kPa}$ and $\eta^{a m p l}=-1.5$

$136 \times 218 \mathrm{~mm}(300 \times 300 \mathrm{DPI})$ 

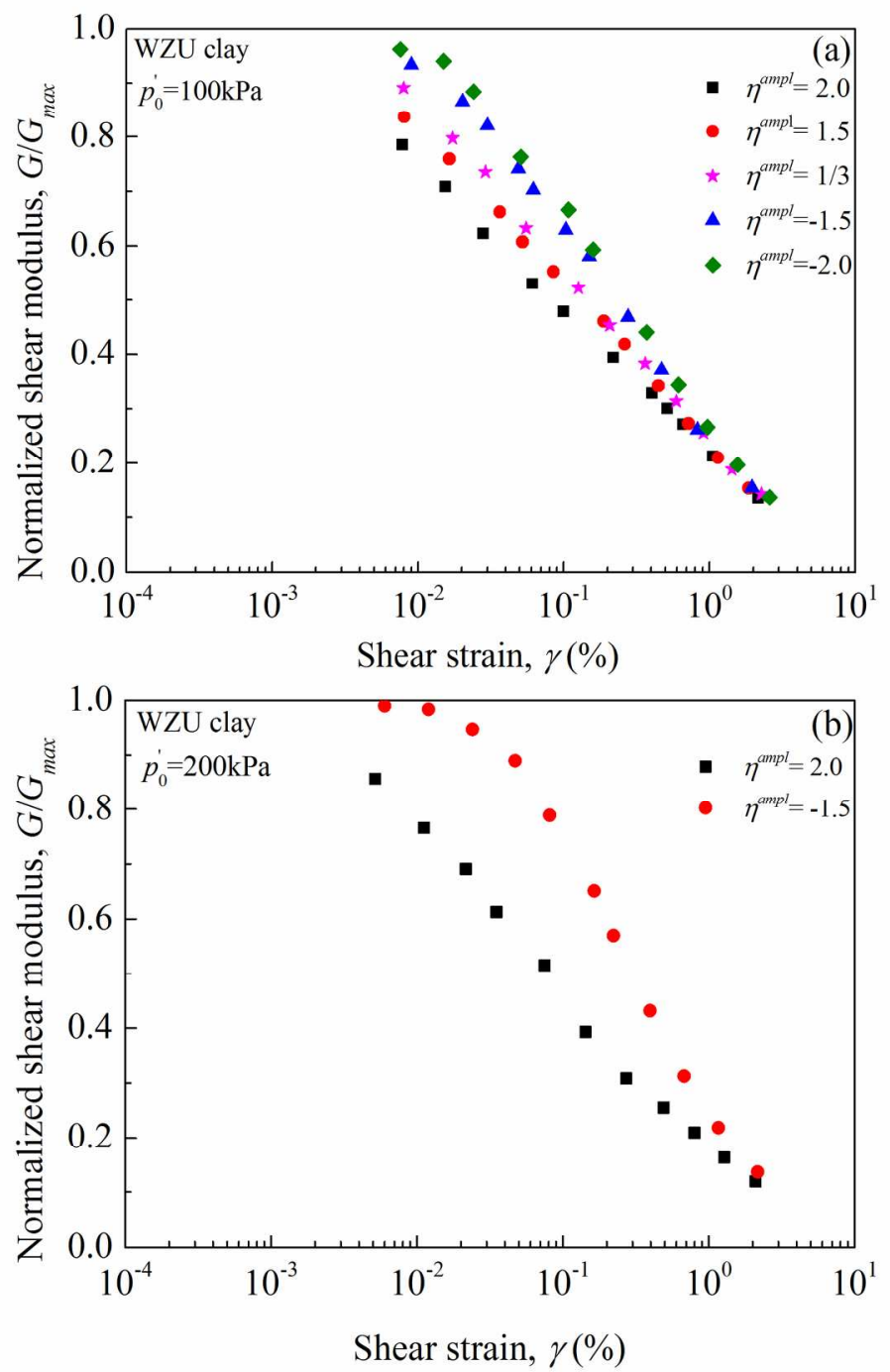

Fig. 5. $G / G_{\max }$ versus $\gamma$ relationships for WZU clay: (a) $p_{0}^{\prime}=100 \mathrm{kPa}$; (b) $p_{0}^{\prime}=200 \mathrm{kPa}$

$$
136 \times 218 \mathrm{~mm}(300 \times 300 \mathrm{DPI})
$$




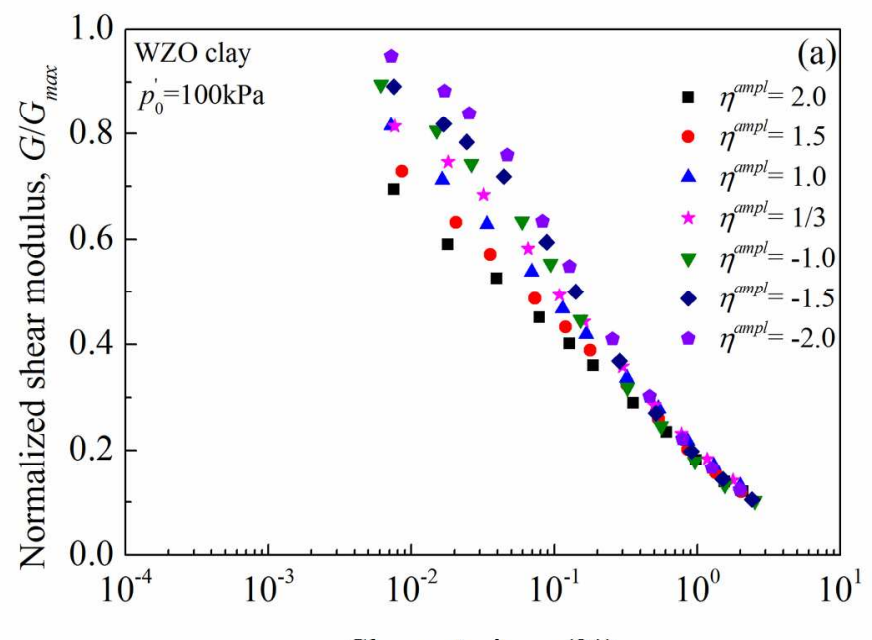

Shear strain, $\gamma(\%)$

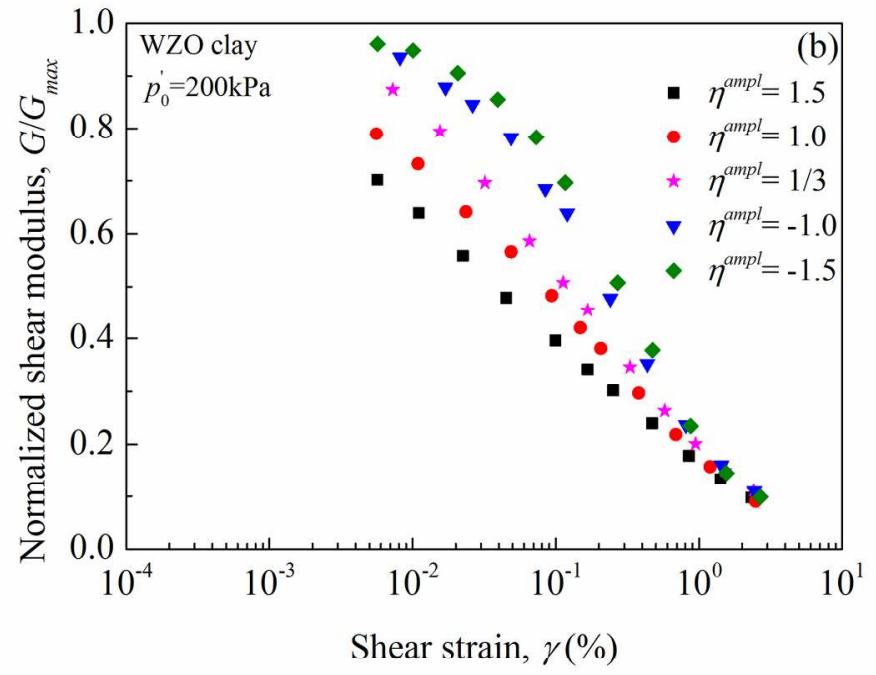

Fig. 6. $G / G_{\max }$ versus $\gamma$ relationships for WZO clay: (a) $p_{0}^{\prime}=100 \mathrm{kPa}$; (b) $p_{0}^{\prime}=200 \mathrm{kPa}$

$$
136 \times 218 \mathrm{~mm}(300 \times 300 \mathrm{DPI})
$$




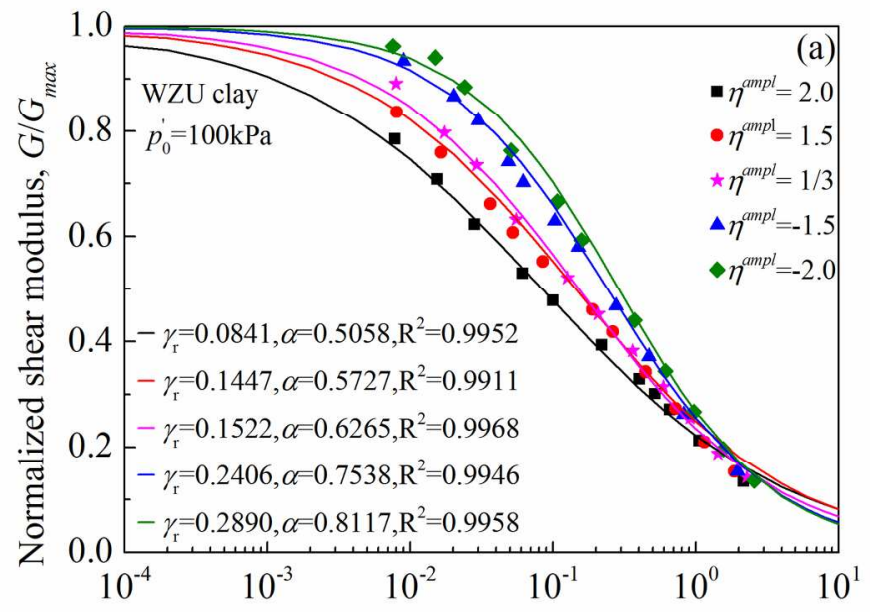

Shear strain, $\gamma(\%)$

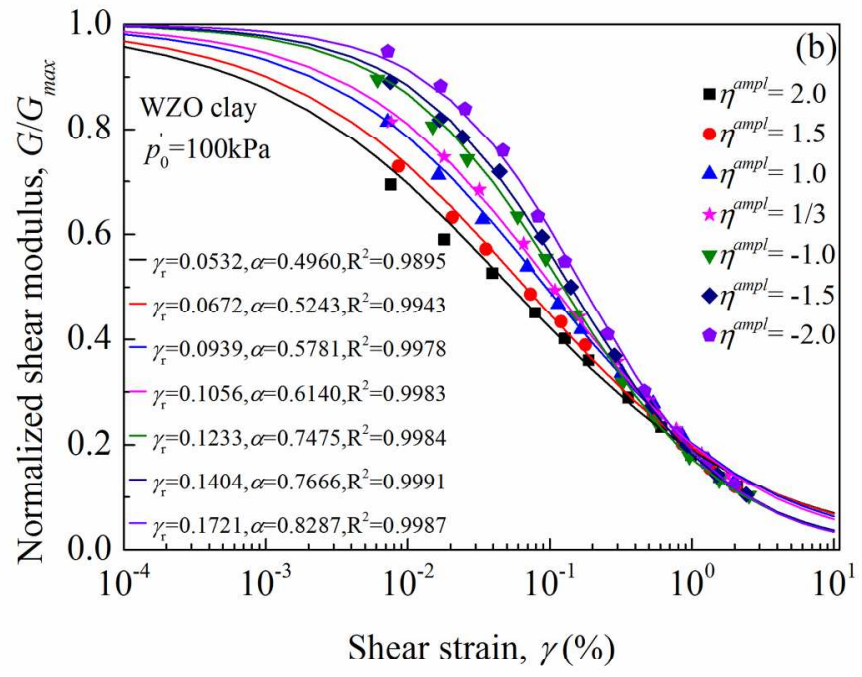

Fig. 7. Comparison between the fitting curves based on Eq. (3) and measured test data for: (a) WZU clay; (b) WZO clay

$136 \times 218 \mathrm{~mm}(300 \times 300 \mathrm{DPI})$ 


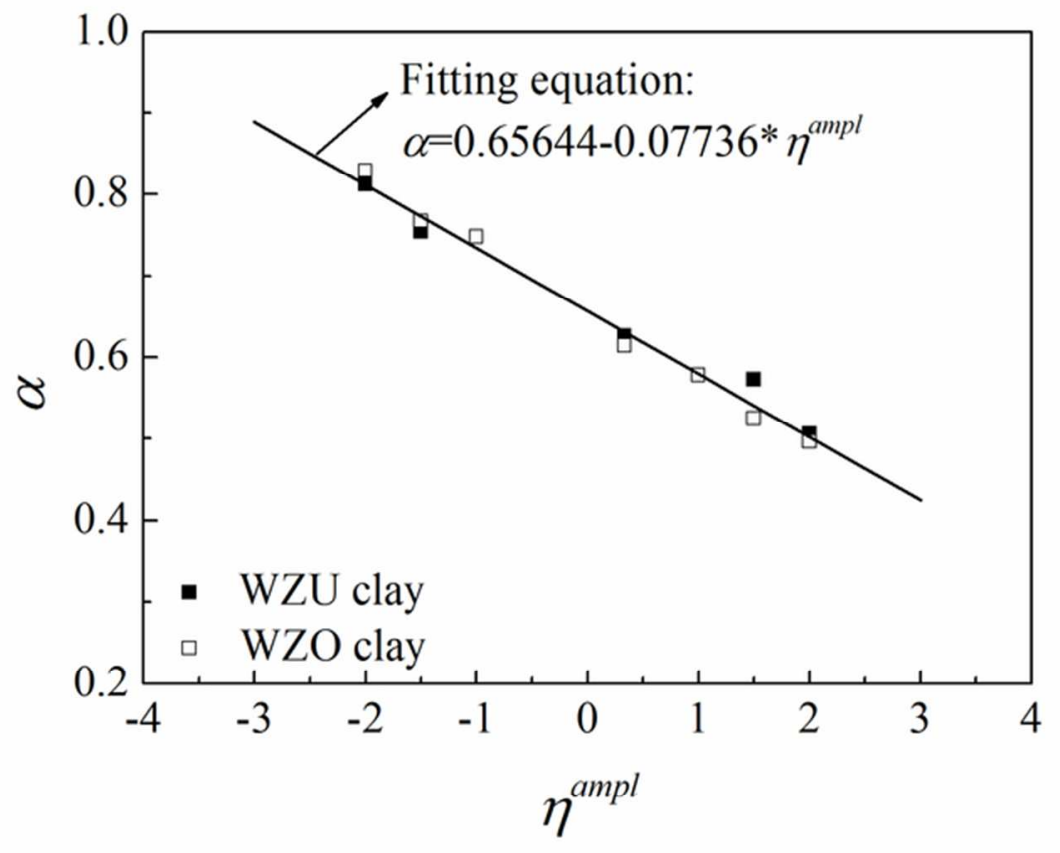

Fig. 8. Relationships between $\alpha$ and $\eta^{a m p l}$

$65 \times 49 m m(300 \times 300$ DPI) 


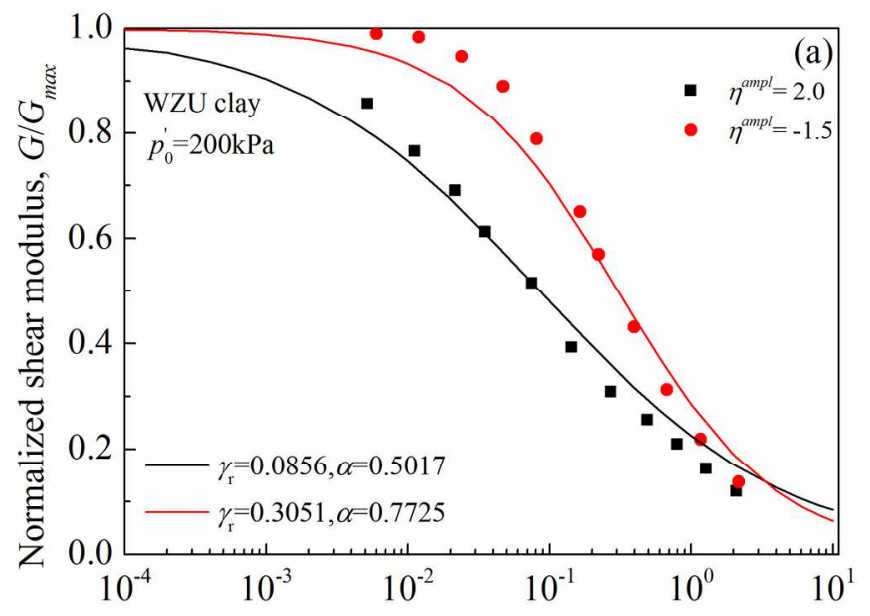

Shear strain, $\gamma(\%)$

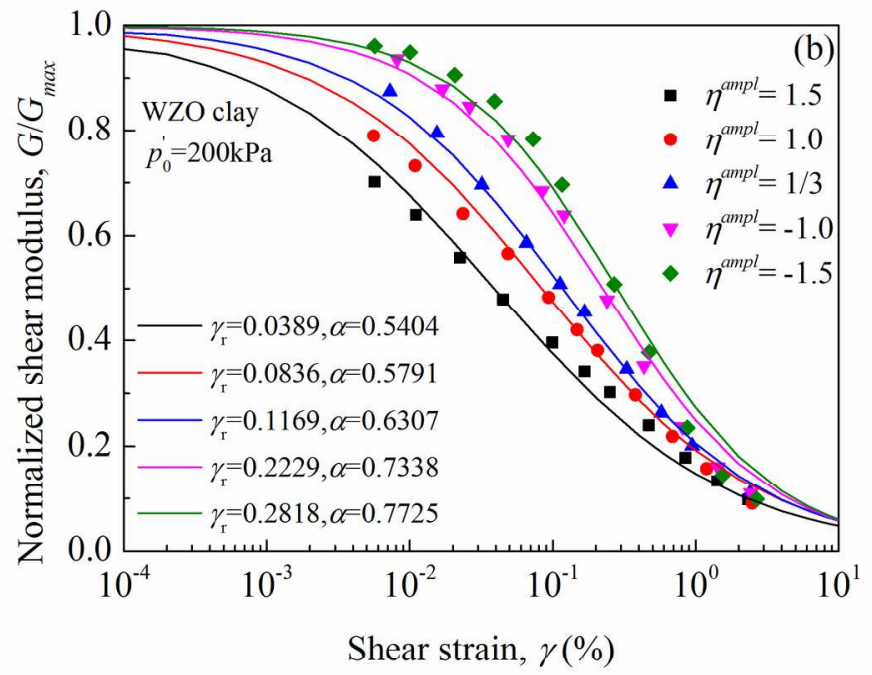

Fig. 9. Comparison between the test data and predicted results for: (a) WZU clay; (b) WZO clay 